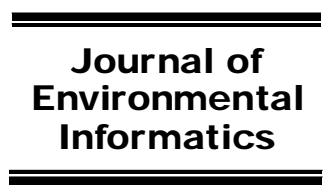

www.iseis.org/jei

\title{
Algorithm for Categorizing Fish Species at Risk
}

\author{
G. K. Tegos ${ }^{1, *}$ and K. Z. Onkov ${ }^{2}$ \\ ${ }^{1}$ General Department, Alexander Technological Educational Institute (A.T.E.I.) of Thessaloniki, Thessaloniki 54101, Greece \\ ${ }^{2}$ Department of Computer Science and Statistics, Agricultural University, 12 Mendeleev, Plovdiv 4000, Bulgaria
}

Received 17 Feburary 2009; revised 14 July 2009; accepted 21 July 2009; published online 7 December 2009

\begin{abstract}
The paper presents an algorithmic approach for analysis of statistical data on quantity of fish catches stored in time series datasets. The developed algorithm applies trend modeling and categorizing rules for processing total data on fish species catches as well as data on fish species catches by areas. This algorithm finds out the fish species that might be at risk and groups them accordingly into the following four categories: a) economical, b) biological, c) biodiversity and d) biological and biodiversity. The analysis of these categories supports planning for future activities referring to the sustainability of the fishery ecosystem in Greece. The presented algorithm is applied on the sea fishery time series data from Greece, but it can also be applied on the same data from other countries or on the same type of integrated data from many countries belonging to big fishing areas (e.g. the Mediterranean Sea) towards data mining of fish species at risk.
\end{abstract}

Keywords: time series datasets, categorizing rules, economical, biological and biodiversity risk, fishery ecosystem

\section{Introduction}

Studies evaluating information gathered by the United Nations and other researchers have scientists alarmed over the state of the world's fisheries. These studies suggest that many species of fish have been depleted to the point where their extinction is a distinct possibility (The people-press, 2007). Nearly a quarter of the commercial species have already been over-exploited, with a total of $70 \%$ of species now being fished close to, at, or beyond their capacity (Eco-logical, 2005). Overfishing has affected the population structure and densities of the demersal fish communities, at least at depths up to $200 \mathrm{~m}$, where most of the fishing activity is focused (Labropoulou and Papaconstantinou, 2004). Some scientists believe that conventional fishing practices put some fish at risk, even though their stocks appear healthy (Berman, 2006).

$\mathrm{EU}$ has to face the same problems that the rest of the world has experienced lately in fishing industries. The biggest one is over-fishing, which results in smaller stocks and landings and therefore smaller incomes. Since fish resources in the EU are a very important part of the human heritage there must be certain regulations to prevent over-fishing. Another problem is the increased competition because of the globalization of the fish products market (Commission of the European

\footnotetext{
* Corresponding author. Tel.: +30 2310 925683; fax: +30 2310925683.

E-mail address: gtegos@gen.teithe.gr (G. K. Tegos).
}

ISSN: 1726-2135 print/1684-8799 online

(C) 2009 ISEIS All rights reserved. doi:10.3808/jei.200900156
Communities, 2001).

It is important to recognize at the start of any discussion of the relevance of marine ecology to fisheries, that a degree of understanding of the ecological context within which a harvesting activity is taking place is essential if adverse impacts of these activities are to be minimized, and the systems ability to support productive human activity is not to be endangered (Caddy and Sharp, 1986).

The classes (categories) used to define the risk of extinction in marine fishes in the wild are as follows: endangered, when a distinct population (DPS) is at high risk of extinction in the immediate future; threatened, when a DPS is not endangered but is facing risk of extinction in the near future; vulnerable, when a DPS is not endangered or threatened but may be at risk of falling into one of these categories in the near future (Musick, 2000). An endangered species is a population of an organism which is at risk of becoming extinct because it is either few in numbers, or threatened by changing environmental or predation parameters (Wikipedia, 2008). There are 29, 300 known species of fish. Under a tenth has been assessed for threatened species status. $40 \%$ of these (800 species) were at risk of global extinction in 2004. Fish species are at risk in almost all territories. The most fish species are at risk in the United States, Mexico, Indonesia and Australia (Kaszala, 2002). The risk of extinction among marine fishes appears to be a real and immediate threat to be addressed (AFS Policy Statement \#31a, 2008). Nowadays, fishing approximates "extermination" with dramatic effects on aquatic ecosystems. Ecosystem management seems the only alternative (Stergiou, 2002). 
The extraordinary declines that have occurred under fishing pressure are almost certainly leading to local extinctions in a manner that can be predicted from intrinsic aspects of their biology. Keeping fish stocks within safe biological limits should keep them safe from extinction (Reynolds et al., 2005). Small changes in harvesting policy may result in large increases in biological and economic risks. For biological risk it is more important to study whether the stock falls below the critical level. However, for the economic risk, a more reasonable measure of risk is how long the fishery is making losses (Lindroos, 2000). The open sea and oceanic fishery activities are related to a certain economical risk, which has increased after the enlargement of the economical zones of many coastal countries. The necessity to increase the fishing efficiency in the open sea has resulted in the development of methods of forecasting the abundant fish stock location (Kudryavtsev, 2008). The objective is how to integrate the fishery data with the economic data in an accounting framework in order to obtain a consistent data set, which can be used for the derivation of a coherent set of indicators and for performing more in-depth analysis of the impact of fishery policies on the economy and environment and economic policies on the fisheries sector (UNFAO, 2004).

Species diversity includes two aspects, the number of species (species richness) and the proportional abundances of the species (heterogeneity diversity). Species richness and heterogeneity diversity can be measured over different scales; a single point, samples, large scales, biogeographical provinces and in assemblages and habitats (Gray, 2000).

An approach for finding fish species at risk is the analysis of statistical data for a relatively long period of time. This data refers to economical activities in fishery sector and is usually stored in large size datasets. The combination of known statistical methods and data mining rules (Onkov and Tegos, 2008), provides the ability of finding important patterns analysis of the Fishery Time Series (FTS) database of Greece (Tegos and Onkov, 2004; Tegos, 2005).

Categorization is designed to enhance resource description by organizing content description so as to enable the reader to grasp quickly and easily what are the main topics discussed in it (Darmoni et al., 2006).

The aim of this work is to present a categorizing algorithm we developed that analyzes fish catches statistical data in order to find out the fish species that might be at risk and group them according to trend modelling and defined rules into four risk categories: a) economic; b) biological; c) biodiversity; and d) biological and biodiversity. Specifically, the algorithm is applied on statistical data concerning sea fish species catches of Greece and the presented results are considered interesting.

\section{Categorizing Algorithm}

The quantity of fish species catches is the basic indicator for each country with a developed fishery. Usually, the collected statistical data by the national statistical institutions for each fish species catches is registered totally and by fishing areas. Statistical data, organized in time series datasets, is the basis for carrying out deep analyses in definite time periods. These datasets are the input of the developed categorizing algorithm (Figure 1). The algorithm includes two procedures and a set of rules. The first procedure applies trend modelling to each time series data representing the total fish species catches. Then each fish species is analyzed according to the adequacy or not of the model and in case of adequacy to the type of the trend-increasing or declining one. The second procedure extracts a dataset of fish species catches by areas and finds out the number of areas with missing catches (zero values). The results of both procedures are analyzed by a set of four rules that gives the opportunity to evaluate fish species that may be at risk and categorizes them accordingly.

The general explanations referring to the rules are as follows. The data concerning the quantity of catches of each fish species from the list (items) is taken into account. The whole studied period of time (P1, P2) is divided into two sub-periods: (P1, Pm) named “old period” and (Pm+1, P2) "last period". Let's denote the average of fish species catches as $U$ for the whole studied period, U1 for the old period and U2 for the last period.

Rule 1 is applied to each fish species with declining trend for the studied period (P1, P2). The ratio $\mathrm{C}$ (Equation 1) estimates the percentage average decline of catches between the "last period" and the "old period":

$C=\frac{U_{1}-U_{2}}{U_{1}} * 100 \%$

Rule 1 gives also the opportunity to differentiate the levels of economical risk as follows:

if $\left|\begin{array}{l|l|l}\mathrm{R} 1 \leq \mathrm{C}<\mathrm{R} 2 \\ \mathrm{R} 2 \leq \mathrm{C}<\mathrm{R} 3 \\ \mathrm{R} 3 \leq \mathrm{C}\end{array}\right| \begin{aligned} & \text { Then item } \in \text { Category I } \\ & \text { (Economical risk) }\end{aligned} \mid \begin{aligned} & \text {-big } \\ & \text {-extremely big }\end{aligned}$

The values of R1, R2 and R3 depend on what can be considered medium, big and extremely big economical risk.

Rule 2 ensures the extraction of fish species with small amount of catches (biological risk). This rule is applied after the application of trend modelling (Figure 1).

Rule 2:

if $\left|\begin{array}{l}\mathrm{U}<\mathrm{L} 1 \text {, in case of no adequate model } \\ \mathrm{U} 2<\mathrm{L} 2 \text {, in case of increasing trend } \\ \mathrm{U} 2<\mathrm{L} 3 \text {, in case of declining trend }\end{array}\right| \begin{aligned} & \text { Then item } \in \text { Category II } \\ & \text { (Biological risk) }\end{aligned}$

It seems logical to assume that the limit L1 is related to a not adequate model and L2 and L3 to the type of fish catches trend-increasing or declining one, respectively. The interrelation L3 > L2 has a practical meaning because the declining trend strengthens the risk. In all cases L1, L2 and L3 are parameters defined by the user. 


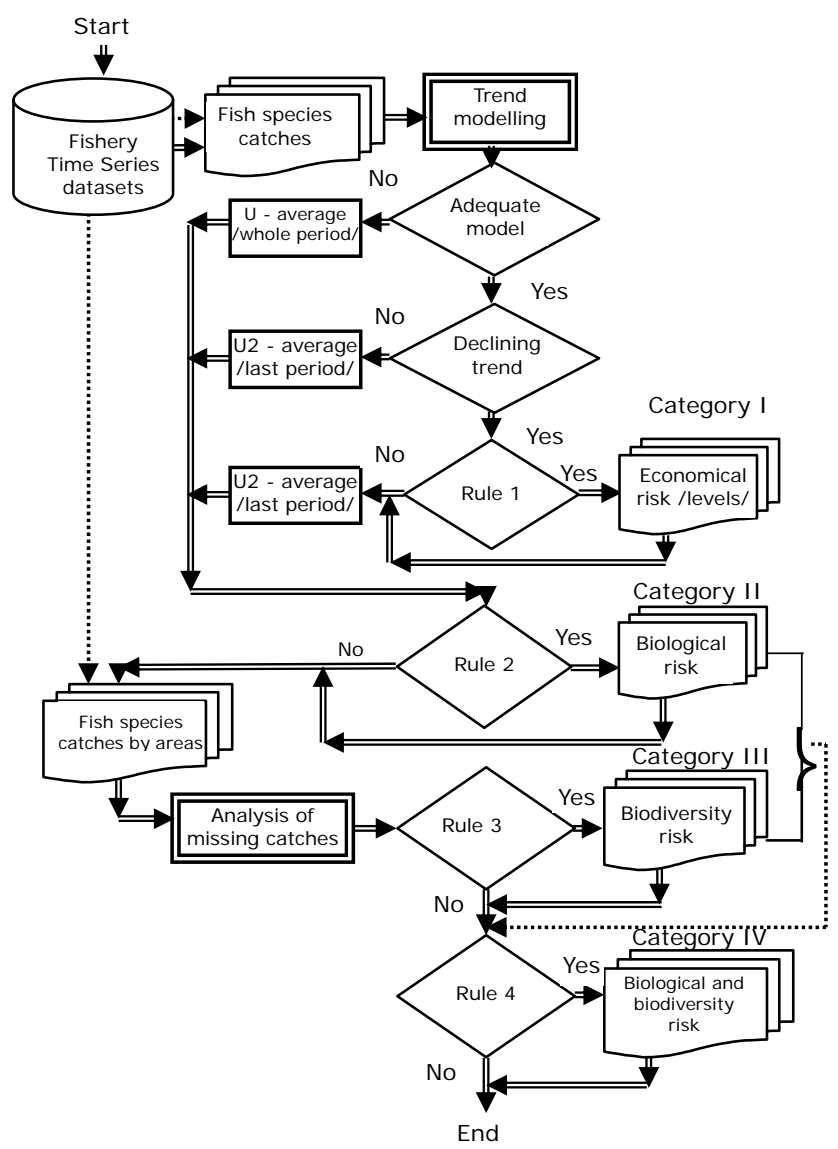

Figure 1. Flowchart of the algorithm for categorizing fish species.

Rule 3 is applied according to the procedure that extracts the fish species with missing catches by areas (Figure 1). The biodiversity here is measured in the sense of "heterogeneity diversity” by biogeographical provinces (fishing areas). Let’s denote by $N$ the number of areas without catches for a certain fish species in the "last year" period.

Rule 3:

\section{If $N>N_{C}$ Then item $\in$ Category III (Biodiversity risk)}

The real value of $\mathrm{N}_{\mathrm{C}}$ depends on the view of biologist about fish biodiversity.

Rule 4:

If [(item $\in$ Category II) and (item $\in$ Category III)]

Then item $\in$ Category IV (Biological and biodiversity risk)

The software is developed by using the known statistical procedures for trend modelling and by creating the software module to apply the categorizing rules. The concrete values for (R1, R2 and R3), (L1, L2 and L3) and $\mathrm{N}_{\mathrm{C}}$ are inserted on the base of knowledge and ideas about fishery in a country regarding the real risk of fish species. The output of the algorithm is the fish species that may be at risk divided into 4 categories.

The developed software gives the opportunity to the experts in fishery, biology, ecology, etc. to study and analyze the pessimistic and optimistic views and expectations and to sup- port decision making regarding the fishery sector.

\section{Application of the Algorithm to the Greek Sea Fishery}

Fishery in Greece plays a very important role in many areas of the Greek state and specifically to the remote ones because it contributes to the maintenance of the social and economic cohesion as well as to the improvement of the economic activities. Countries as Greece surrounded by sea are obliged to support the sustainability of sea fishery in order for sea food to be sufficient not only for domestic consumption but also for exports to other countries, decreasing so the deficit and contributing to the financial balance of the country (Tegos and Onkov, 2006). Fisheries activities, on the other hand, have a strong impact on the structure of the ecosystems and the patterns of biodiversity (GTSI, 2007).

The developed categorizing algorithm and the corresponding software are applied on the sea fishery data in Greece, stored in Fishery Time Series (FTS) database mentioned above. This database includes statistical data for 71 fish species caught from the 18 Greek fishing areas. Figure 2 presents the total quantity of fish catches in Greece for the time period 1994 2005. This time period is divided into two sub-periods: 1994 $\sim 2001$ with declining catches (old period) and $2002 \sim 2005$ with sustainable catches (last period).

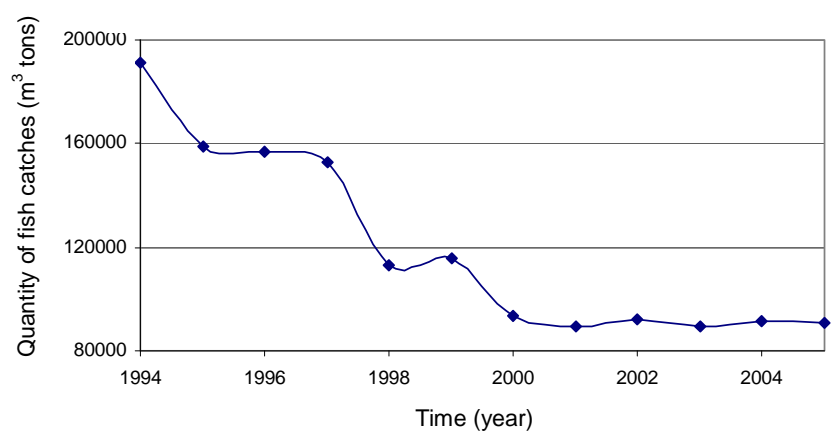

Figure 2. Total fish catches in Greece for the studied period 1994-2005.

The estimated ratio $\mathrm{C}$ (the percentage average decline) for total fish catches shows a $32.13 \%$ decline. It appears rational to use this value as the basis in order to find all fish species having a declining trend and value of $\mathrm{C}$ greater than the total one. Hence, the concrete values for the parameters of rule 1 can be as follows: $\mathrm{R} 1=32 \%, \mathrm{R} 2=50 \%$ and R3 $=80 \%$. Both, the number and the names of Greek fish species at different levels of economical risk are presented in Table 1 . The attained results show that $52 \%$ of fish species are at economical risk and the analysis from biological and ecological aspects is a necessity for fish species with great catches decline and especially the ones that are found to be at big and extremely big economical risk.

Figure 3 represents graphically the fish catches for Thornback ray, Daouki and Oyster. These fish species are at different levels of economical risk-middle with $32 \sim 50 \%$ decline, big 
Table1. Fish Species in Greece at Economical Risk

\begin{tabular}{llll}
\hline Rule 1 & C & $\begin{array}{l}\text { Number of fish } \\
\text { species at risk }\end{array}$ & Fish species in category I \\
\hline medium & $32-50 \%$ & 23 & $\begin{array}{l}\text { Thornback ray, Gurnard, Tub fish, Bogue, Club mackerel, Pickerel, Red mullet, } \\
\text { Croaker, Pilchart, Scorpion fish, Mackerel, Tune fish, Blotched pickerel, Lobster etc } \\
\text { Garfish, Shapper, Red bream, Daouki, Guitarfish, Jack mackerel, Horse mackerel, } \\
\text { big }\end{array}$ \\
$\begin{array}{llll}\text { Black see bream, Comber, and Warty venus } \\
\text { Mussel, Oyster, Bay scallop, and Others }\end{array}$ \\
\hline
\end{tabular}

Table 2. Fish Species in Greece at Biological Risk

\begin{tabular}{llll}
\hline Rule 2 & Totally analyzed & Number of fish species at risk & Fish species in category II \\
\hline No adequate model & 10 & 4 & Stone bass, Grouper, Eel, and Crab \\
Increasing trend & 4 & - & - \\
Declining trend & 57 & 5 & Brill, Croaker, Guitarfish, Oyster, and Bay scallop \\
\hline
\end{tabular}

Table 3. Fish Species in Greece at Biodiversity Risk

\begin{tabular}{lll}
\hline Rule 3 & Number of fish species at risk & Fish species in Category III and number of areas without catches (in brackets) \\
\hline $\begin{array}{l}\text { Biodiversity } \\
\text { risk }\end{array}$ & 12 & $\begin{array}{l}\text { Garfish (5), Brill (4), Daouki (7), Sprat (5), Skipjack (4), Guitarfish (12), Eel } \\
\text { (6), Crab (6), Warty venus (9), Mussel (13), Oyster (11), and Bay scallop (12) }\end{array}$ \\
\hline
\end{tabular}

Table 4. Fish Species in Greece at Biodiversity and Biological Risk

\begin{tabular}{llll}
\hline Rule 4 & $\begin{array}{l}\text { Number of fish } \\
\text { species at risk }\end{array}$ & $\begin{array}{l}\text { Fish species in Category IV and number of } \\
\text { areas without catches (in brackets) }\end{array}$ & $\begin{array}{l}\text { Fish species in Category IV and average value } \\
\text { of catches (U2) for the period 2002-2005 (in } \\
\text { brackets) }\end{array}$ \\
\hline $\begin{array}{l}\text { Biological and } \\
\text { biodiversity risk }\end{array}$ & 6 & $\begin{array}{l}\text { Brill (4), Guitarfish (12), Eel (6), Crab (6), } \\
\text { Oyster (11), and Bay scallop (12) }\end{array}$ & $\begin{array}{l}\text { Brill (68.48), Guitarfish (37.13), Eel (17.35), } \\
\text { Crab (111.95), Oyster (36.15), and Bay scallop } \\
(10.98)\end{array}$ \\
\hline
\end{tabular}

with $51 \sim 80 \%$ decline and extremely big with $>80 \%$ decline, respectively.

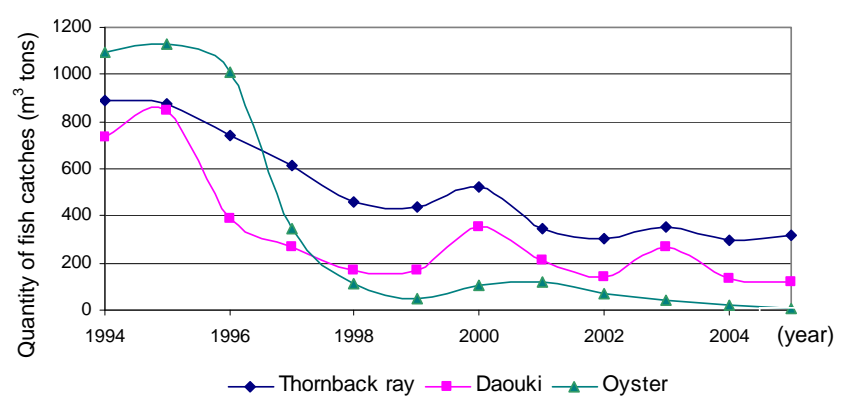

Figure 3. Fish species at different levels of economical risk.

Categorization of fish species at biological risk is carried out by putting the following limit values in rule 2 : $\mathrm{L} 1=150$, $\mathrm{L} 2=50$ and $\mathrm{L} 3=100 \mathrm{~m}^{3}$ tons. Table 2 presents the fish species at biological risk in Greece according to the mentioned conditions. The analysis shows that totally 9 fish species are at biological risk: 4 without adequate model and 5 with declining trend. These 9 fish species represent the $12.7 \%$ of all statistically registered fish species in Greece. This result is not considered to be so bad in comparison with the global results; nevertheless it requires the special attention of experts in order for the deterio- ration of this situation to be avoided in the future.

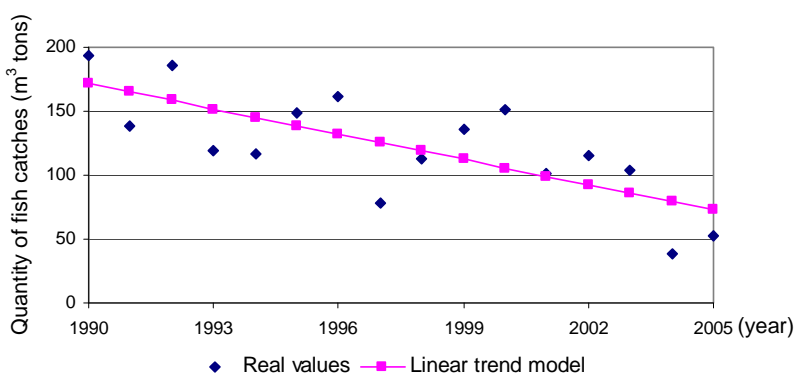

Figure 4. Linear trend model for Croaker fish.

Figure 4 shows the graphical presentation of quantities of catches of the fish species Croaker produced by the linear trend model for the $1990 \sim 2005$ period. The continuous decline of the quantity of catches of the Croaker fish species is obvious for the whole period. It has placed this fish species at biological risk (Table 2) and consequently at medium economical risk (Table 1).

Rule 3 is constructed in order to find out the fish species with missing catches in many areas. Table 3 shows that there are 12 fish species at Biodiversity risk. A fish species is consi- 
dered to be at biodiversity risk if it is missing in the "last year" catches in 4 or more areas. It is needed to point out that 5 fish species - Guitarfish (Figure 4), Warty venus, Mussel, Oyster and Bay scallop have missing catches in more than 8 fishing areas (50\%) of Greece. These results are considered to be useful for experts being able to make a deep analysis in biology and ecology.

Category IV is the algebraic section of the Categories II and III. The obtained results for Category IV are presented in Table 4. Here there are 6 fish species at biological and biodiversity risk. Three fish species - Guitarfish, Oyster and Bay scallop are at a great biological and biodiversity risk because there are no fish catches in many areas ( $>10)$ for these species and at the same time there is an extremely small quantity of catches due to a probably very low population. The quantity of catches for these three fish species is considered to be extremely small because they have a declining trend (see Table 2) and a U2 $=37.13$, 36.15, 10.98, respectively, that is less than the limit value L3 $=50$ (rule 2).

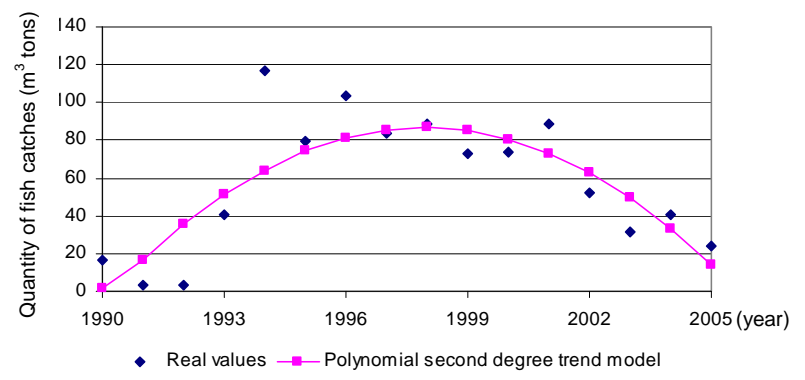

Figure 5. Polynomial second degree trend model for Guitarfish.

Figure 5 shows the graphical presentation of quantities of catches of the fish species Guitarfish produced by the polynomial second degree model for the 1990 2005 period. A dramatic decline of the quantity of Guitarfish is obvious in the graph for the $2000 \sim 2005$ period. An indication for this decline is the missing catches of this fish species in 12 fishing areas of Greece in the "last year" period. The declining trend and the missing catches in the above areas puts the fish species at biological and biodiversity risk and consequently at big economical risk (Table 1).

One argument for focusing conservation efforts in areas supporting high numbers of species thought to be at risk of extinction is that these areas represent places where species are likely to be extirpated from the species pool in the future. If there is any merit to this expectation, then one would predict recent extirpations to be associated with those areas currently supporting concentrations of rare species or species at-risk (Flather et al., 2008).

An ecological measure may be the departure of factories that are close to the seas, the biological cleaning of overrun, penalties to the polluters of the seas, monitoring of fishing tools and prohibiting those that cause ecological problems, etc.

A biological measure that may relief ecologically the areas is the artificial breeding of this type of fish species and enriching with their prawns these problematic areas, with the precondition that the mentioned measures are applied.

\section{Conclusions}

The developed categorizing algorithm for analysis of statistical time series data on fish species catches combines trend modelling and categorizing rules. It groups fish species that might be at risk in four categories: a) economical,b) biological, c) biodiversity and d) biological and biodiversity. The results of the application of this algorithm to fishery time series data of Greece are considered useful for experts in order to implement pessimistic and optimistic views and expectations as well as to plan future activities respecting the sustainability of the fishery ecosystem. This algorithm can be easily improved and applied on time series data of different countries as well as on same integrated data of many countries belonging to big fishing areas (e.g. the Mediterranean Sea) for categorizing fish species at risk. This type of data analysis may result in taking common economical, biological and ecological measures in the field of fishery with a more global significance.

Acknowledgments. The authors wish to thank all anonymous reviewers for their constructive and valuable comments and suggestions.

\section{References}

AFS Policy Statement \#31a, (2008). Protection of Marine Fish Stocks at Risk of Extinction. www.fisheries.org/afs/docs/policy_31af.pdf (accessed January 21, 2009).

Berman, J. (2006). Study: Conventional Fishing Practices Put Some Fish at Risk. J. Nature. www.voanews.com/english/2006-10-19voa 67.cfm (accessed November 4, 2008).

Caddy, J.F., and Sharp, G.D. (1986). An ecological framework for marine fishery investigations, FAO Fish. Tech. Pap., 283,152.

Commission of the European Communities (2001). Green Paper of 20 March 2001 on the future of the Common Fisheries PolicyVolume I - COM (2001) 135 final-http://europa.eu.int/comm/ fisheries/ greenpaper /green/volume1_en.pdf.

Darmoni, S.J., Névéol, A., Renard, J.M., Gehanno, J.F., Soualmia, L.F., Dahamna, B., and Thirion, B. (2006). www.ncbi. nlm.nih. gov/pubmed/16464249.

Eco-logical (2005). The Causes and Effects of Overfishing. www. grinningplanet.com/2005/06-07/overfishing-article.htm (accessed January 20, 2009).

Flather, C.H., Knowles, M.S., and McNees, J. (2008). Geographic Patterns of At-Risk Species, www.fs.fed.us/rm/pubs/rmrs_gtr211 pdf.

Gray, J.S. (2000). The measurement of marine species diversity, with an application to the benthic fauna of the Norwegian continental shelf, J. Exp. Mar. Biol. Ecol., 250(1-2), 23-49.

Greek Technology and Science Initiatives (GTSI) (2007). An Initiative of the Greek Research Centres. http://www.iceht.forth.gr/ news/docs/GTSI_June_2007pdf.pdf (accessed January 21, 2009).

Kaszala, E. (2002). Fish at Risk. SASI Group (Sheffield Un) \& Mark Newman(Michigan Un). www.worldmapper.org/posters/worldmapper_map276_ver5.pdf (accessed January 21, 2009).

Kudryavtsev, V.N. (2008). Remote Sensing of the Sea Department, Marine Hydrophysical Institute. www.mhi.iuf.net/odmi/odmi.htm (accessed January 2, 2009). 
Labropoulou, M., and Papaconstantinou, C. (2004). Community structure and diversity of demersal fish communities: the role of fishery, Fisheries \& Environment-Scientia Marina , 68 (Suppl.1), 215-226.

Lindroos, M. (2000). Cooperation and conflicts in high seas fisheries, Helsinki School of Economics and Business Administration, dissertation work.

Musick, J.A. (2000). Criteria to Define Extinction Risk in Marine Fishes, Fisheries, 24, 12.

Onkov, K., and Tegos, G. (2008). Algorithmic Solution for Analysis of Time Series Database, Proceedings, HAICT A 2008 4-th International Conference "Information \& Communication Technologies in Bio \& Earth Sciences”, pp. 158-162.

Reynolds, J.D., Dulvy, N.K., Goodwin, N.B., and Hutchings, J.A. (2005). Biology of extinction risk in marine fishes, Proc. Biol. Sci., 272(1579), 2337-2344.

Stergiou, K.I. (2002). Overfishing, tropicalization of fish stocks, uncertainty and ecosystem management: resharpening Ockham's razor, Fish. Res., 55(1-3), 1-9.

Tegos, G.K. (2005). PC-Information System concerning sea fishery time series in $\mathrm{Gr}$ eece, $\mathrm{PhD}$ thesis, Computer science department, Agricultural University, Plovdiv, Bulgaria.

Tegos, G.K., and Onkov, K.Z. (2004). Ecological aspects of data series computer analysis concerning quantities of sea fish catches in Greece by principal species and fishing areas, Journal of Environmental Protection and Ecology, 5(4), 836-843.

Tegos, G.K., and Onkov, K.Z. (2006). Seasonality Assessment Based on Embedded Software in the PC Time Series Database for Greek Sea Fishery, HAICTA conference proceedings, Bolos, Greece, 792800.

The people-press (2007). Fishing the Seas to Extinction, vol. 117, No 5. www.slp.org/pdf/thepeople/jan_feb_07TP.pdf (accessed January 20, 2009).

UNFAO (2004). Integrated Environmental and Economic Accounting for Fisheries. United Nations FAO of the United Nations Series F, No.97 (ST/ESA/STAT/SER.F/97). http://unstats.un.org/unsd/env Accounting/Fish_final_whitecover.pdf (accessed October 17, 2008).

Wikipedia (2008). Endangered species. http://en.wikipedia.org/wiki/ Endangered_species (accessed January 21, 2009). 